\title{
Pituitary Adenoma: A Short Illustrative Review
}

\author{
Sharada Rane ${ }^{1}$ Anita Kavatkar ${ }^{1} \quad$ Almas Pathan $^{1}$ Shaila Puranik ${ }^{1}$ \\ ${ }^{1}$ Department of Pathology, Byramjee Jeejeebhoy Government \\ Medical College, Pune, Maharashtra, India

\begin{abstract}
Address for correspondence Dr. Anita N. Kavatkar, MD, P301, Pinnac Memories Phase II, Sr No. 23/3 + 4, Near Rahul Nagar, Kothrud, Pune,
\end{abstract} \\ Maharashtra 411038, India (e-mail: kavatkaranita@rediffmail.com).
}

Indian J Neurosurg 2016;5:180-182.
Abstract
Keywords
- pituitary
- adenoma
- macroadenomas
- microadenomas

The pituitary gland is located below the brain in a depression of sphenoid bone known as sella turcica. It controls most of the body's endocrine functions via the secretion of various hormones into the circulatory system. Pituitary tumors are typically found in the anterior part of the gland. Almost all are benign adenomas. Tumors of size $10 \mathrm{~mm}$ or less are designated as microadenomas and those exceeding $10 \mathrm{~mm}$ in size are defined as macroadenomas. We report a case of resected pituitary macroadenoma. The diagnosis was made after histopathologic examination and clinicopathologic correlation.

\section{Introduction}

The pituitary gland is situated in a depression of the sphenoid bone called the sella turcica. It is composed of two parts: the anterior pituitary and the posterior pituitary. The anterior pituitary secretes several hormones: PRL (prolactin), ACTH (adrenocorticotrophic hormone), TSH (thyroid-stimulating hormone), FSH (follicle-stimulating hormone), LH (luteinizing hormone), and GH (growth hormone) whereas the posterior pituitary secretes vasopressin and oxytocin. On light microscopic examination using H\&E (hematoxylin and eosin) stain, cells of the anterior pituitary are arranged in cords surrounded by a network of capillaries. These cells are traditionally classified as acidophilic, basophilic, or chromophobic. The current classification of these cells is based on immunohistochemistry and electron microscopic features and gives an insight into their function. They are classified as somatotrophs, lactotrophs, corticotrophs, gonadotrophs, and thyrotrophs. ${ }^{1}$

Pituitary tumors are typically found in the anterior part of the gland. Almost all are benign adenomas. Tumors larger than $10 \mathrm{~mm}$ are called macroadenomas whereas those less than $10 \mathrm{~mm}$ are called microadenomas. They may be incidental findings at autopsy, may present with endocrine effects due to hormones secreted, or present with mass effects due to local spread in the cranial cavity.

We report the case of a functioning pituitary macroadenoma that was resected. The case was studied with special reference to clinical presentation, morphologic features, and clinicopathologic correlation. H\&E stain was done on paraffin sections of $4 \mu \mathrm{m}$ thickness. Histopathology was correlated with clinical features and radiologic findings, including magnetic resonance imaging (MRI) and hormone levels in blood.

\section{Case Report}

A 35-year-old man, a known case of acromegaly, presented with headache, frontal bossing, thickened palmar, and plantar pads. Hormonal assay showed GH $40 \mathrm{ng} / \mathrm{mL}$ and PRL $75 \mathrm{ng} / \mathrm{mL}$. MRI findings showed a mass arising in sella turcica and extending in the suprasellar region and cavernous sinuses, of size $6.7 \times 5.3 \times 4 \mathrm{~cm}$. The tumor had a diffuse pattern of growth in H\&E-stained histopathology sections (-Fig. 1). The diagnosis after histopathologic examination and clinicopathologic correlation was pituitary somatotrophic adenoma.

\section{Discussion}

Pituitary adenomas are tumors arising from the pituitary gland. They are classified as macroadenomas $(>10 \mathrm{~mm})$ or microadenomas $(<10 \mathrm{~mm})$. Incidental or subclinical adenomas are found in nearly $25 \%$ of autopsies. ${ }^{1}$ Small pituitary tumors that are not apparent are reported in 5 to received

April 8, 2015

accepted after revision

February 3, 2016

published online

July 14,2016
DOI http://dx.doi.org/

10.1055/s-0036-1584600. ISSN 2277-954X (c) 2016 Neurological Surgeons' Society
of India

License terms

$\Theta(1) \Theta$ 


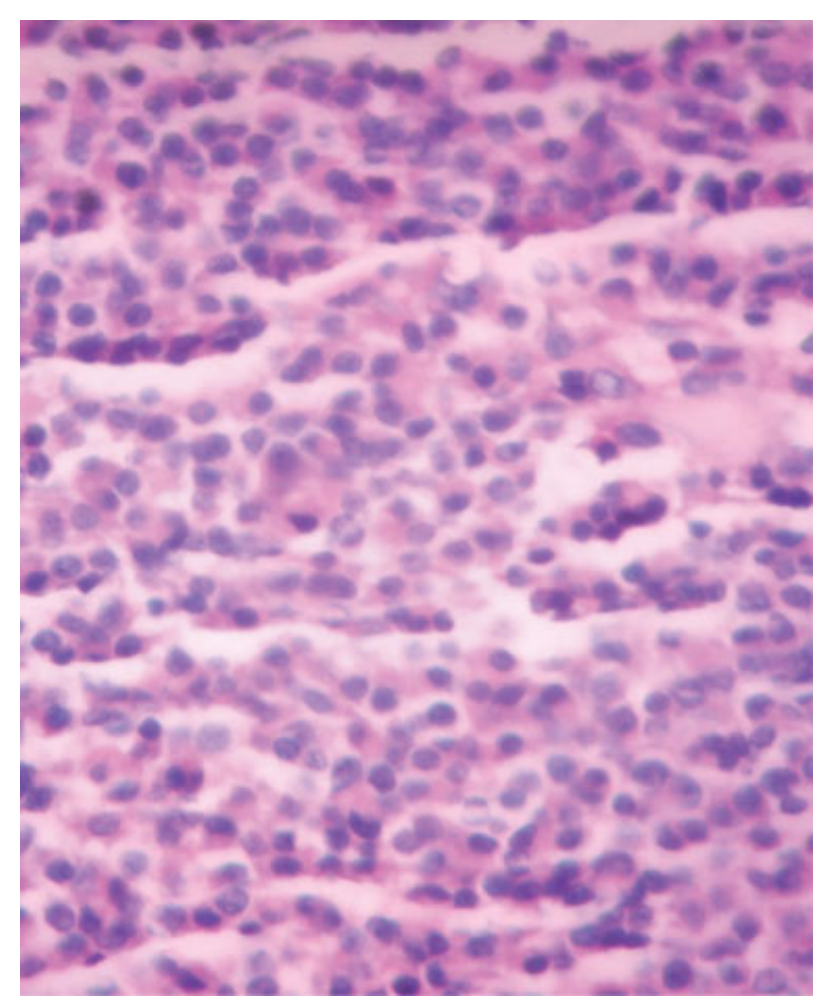

Fig. 1 Microscopic appearance of pituitary adenoma. H\&E stain $(\times 450)$.

$20 \%$ of routine autopsies. ${ }^{2}$ The clinical presentation is varied and depends on hormones secreted and local effects in the cranial cavity. Some pituitary tumors are associated with multiple endocrine neoplasia (MEN) type $1 .^{1}$ Endocrine defects depend on the hormones secreted, for example, acromegaly, amenorrhea, galactorrhea, etc. Neurologic symptoms include headache, impairment of vision, etc.

An overall male preponderance has been reported in the literature. In one study, there were 145 males and 115 females out of a total of 260 patients. $^{3}$ The male-to-female ratio was 41:34 in another series. ${ }^{4}$ The symptoms were the maximum in the fifth decade of life in both sexes, and the ages were between 14 and 72 years. ${ }^{3}$ Incidence rates were higher in females during early life and higher in males in later life. ${ }^{5}$

Pituitary adenomas account for approximately 10 to $20 \%$ of all intracranial neoplasms in neurosurgical series. ${ }^{1}$ The prevalence of clinically relevant pituitary adenomas has been identified as $94 \pm 19.3$ cases per 100,000 population. ${ }^{6}$ The prevalence of pituitary tumors has been studied by radiologic methods and autopsy studies. In one metaanalysis, the estimated prevalence of pituitary adenoma in autopsy studies was $14.5 \%$ and in radiographic studies it was approximately $22.5 \%{ }^{7}$ The overall estimated prevalence of pituitary adenomas across both groups of studies was $16.7 \% .^{7}$ Acromegaly has been reported in 19 out of 260 cases $^{3}$ and 44 out of 75 cases. $^{4}$

Serum PRL levels are usually greater than $100 \mathrm{ng} / \mathrm{mL}$ in patients with pituitary macroadenomas. In up to 15 to $20 \%$ of these patients, levels less than this may be found. ${ }^{8}$ PRL level in female patients with pituitary adenomas has been reported as between 90 and $1,800 \mathrm{ng} / \mathrm{mL}$, with an average value of $390 \mathrm{ng} / \mathrm{mL} .{ }^{9}$ In males, the levels were between 216 and $15,800 \mathrm{ng} / \mathrm{mL}$, with an average value of $5,838 \mathrm{ng} / \mathrm{mL}^{9}{ }^{9}$

In healthy individuals, 70 to $80 \% \mathrm{GH}$ results are less than 1 $\mathrm{ng} / \mathrm{mL}$, but up to 20 to $40 \mathrm{ng} / \mathrm{mL}$ during normal secretory peaks, for example, during sleep, exercise, fasting, etc. In healthy adults, during GTT (glucose tolerance test), glucose load suppresses $\mathrm{GH}$ secretion to less than $1 \mathrm{ng} / \mathrm{mL}$, but a secondary rise occurs several hours later. ${ }^{8}$ Random GH sampling is not adequate to establish the diagnosis of acromegaly.

In the present case, the tumor has presented with acromegaly and is a somatotrophic tumor. Clinical features and hormonal assay were useful in the diagnosis.

Pituitary tumors have been classically described as being of acidophil, basophil, or chromophobe types based on histology and staining characteristics. However, these are not useful to find out the functional status of the tumor. Sinusoidal or papillary pattern has been described in some tumors, but the pattern does not help in identifying the type of tumor. Most of GH- and PRL-producing adenomas, clinically nonfunctioning null cell adenomas, and oncocytomas show a diffuse pattern of growth. ACTH- and FSH/LH-producing tumors show a predominantly sinusoidal pattern of growth. A papillary pattern is seen in some PRL and LH/FSH tumors. PAS stain is positive in basophil adenomas that generally secrete ACTH. ${ }^{2}$ In this case, the tumor had a diffuse pattern of growth.

Immunohistochemistry and electron microscopy are used to characterize the tumors based on the hormones they secrete. Thus these tumors are classified as prolactinomas, lactotroph adenoma, corticotroph adenoma, etc. ${ }^{2}$ Some of the tumors secrete more than one hormone while clinical effects of excess secretion of only one type of hormone may be apparent. PRL-secreting tumors have been found to be more common than GH- or ACTH-secreting pituitary adenoma. ${ }^{7}$ However, in a resource-limited setting, clinical features and hormonal assays can give an idea about the functional status of the tumor cells, as in the present case.

In adult autopsy material, an almost equal percentage of PRL-producing tumors and clinically nonfunctioning tumors is found. In surgical material, these two groups are less prominent. ${ }^{2}$ In this case, the tumor was functional and led to the clinical presentation of acromegaly.

Histologic features are not helpful to predict the risk of recurrence. In one study, immunohistochemical overstaining for pRB protein, cyclin D1, MIB-1, and p53, and normostaining for $\mathrm{p} 16$ have been associated with recurrence. ${ }^{10}$ The invasion of sellar bone or dura is found in 20 to $80 \%$ of pituitary adenomas. ${ }^{1}$ Invasion of the cavernous sinuses is more important from the point of view of recurrence and planning of treatment. Pituitary carcinoma is rare and diagnosed when there is discontinuous spread in the cerebrospinal space, extracranial metastasis, or gross brain invasion. ${ }^{1}$

To summarize, in this case of pituitary macroadenoma, the presentation of acromegaly, hormonal assays were helpful in the diagnosis along with radiologic features and histopathology. This is important in a resource-limited setting. 


\section{Author Contributions}

The primary authors take responsibility for the integrity of the work as a whole from inception to published article and should be designated as "guarantors." Dr. Sharada Rane, Dr. Anita Kavatkar, and Dr. Almas Pathan were involved in concept, design, definition of intellectual content, literature search, data acquisition, data analysis, manuscript preparation, manuscript editing, and manuscript review. Dr. S.C. Puranik was involved in manuscript editing and manuscript review.

\section{Conflict of Interest}

None.

\section{Statement}

The manuscript has been read and approved by all the authors, the requirements for authorship have been met, and each author believes that the manuscript represents honest work.

\section{Workplace}

Department of Pathology, B.J. Government Medical College, Pune, Maharashtra, India.

\section{Paper Presentation}

Presented in part as poster at MAPCON 2012 conference. (Maharashtra Chapter conference of IAPM [Indian Association of Pathologists and Microbiologists]).

\section{References}

1 Scheithauer BW. The pituitary and sellar region. In: Mills SE, Carter D, Greenson JK, Oberman HA, Reuter V, Stoler MH, eds. Sternberg's Diagnostic Surgical Pathology. 4th ed. Philadelphia, PA: Lippincott Williams and Wilkins; 2004: 521-556

2 Ricardo V, Eva HL, Stefaneanu L, Kovacs K. Pituitary gland. In: Damjanov I, Linder J, eds. Andersons Pathology. 10th ed. St Louis, MO: Mosby; 1996:1919-1942

3 Elkington SG. Pituitary adenoma. Preoperative symptomatology in a series of 260 patients. $\mathrm{Br} \mathrm{J}$ Ophthalmol 1968;52(4): 322-328

4 Zargar AH, Laway BA, Masoodi SR, et al. Clinical and endocrine aspects of pituitary tumors. Saudi Med J 2004;25(10): 1428-1432

5 McDowell BD, Wallace RB, Carnahan RM, Chrischilles EA, Lynch CF, Schlechte JA. Demographic differences in incidence for pituitary adenoma. Pituitary 2011;14(1):23-30

6 Daly AF, Rixhon M, Adam C, Dempegioti A, Tichomirowa MA, Beckers A. High prevalence of pituitary adenomas: a crosssectional study in the province of Liege, Belgium. J Clin Endocrinol Metab 2006;91(12):4769-4775

7 Ezzat S, Asa SL, Couldwell WT, et al. The prevalence of pituitary adenomas: a systematic review. Cancer 2004;101(3): 613-619

8 Howanitz JH, Henry JB. Evaluation of endocrine function. In: Henry JB, ed. Clinical Diagnosis and Management by Laboratory Methods. 20th ed. Philadelphia, PA: WB Saunders; 2001: 304-334

9 Mukai K. Pituitary adenomas. Immunocytochemical study of 150 tumors with clinicopathologic correlation. Cancer 1983;52(4): 648-653

10 Lee EH, Kim KH, Kwon JH, Kim HD, Kim YZ. Results of immunohistochemical staining of cell-cycle regulators: the prediction of recurrence of functioning pituitary adenoma. World Neurosurg 2014;81(3-4):563-575 